EXTENDED REPORT

\title{
High prevalence of osteoarthritis 14 years after an anterior cruciate ligament tear in male soccer players: a study of radiographic and patient relevant outcomes
}

\author{
A von Porat, E M Roos, H Roos
}

Ann Rheum Dis 2004;63:269-273. doi: 10.1136/ard.2003.008136

See end of article for authors' affiliations

\section{Correspondence to:} Anette von Porat, Sport Medicine Centre, Södra Tvärgången 3, S-252 54 Helsingborg, Sweden; anette.vonporat@telia.com

Accepted 14 June 2003

\begin{abstract}
Objective: To identify the consequences of an anterior cruciate ligament $(\mathrm{ACL})$ tear in a cohort of male soccer players 14 years after the initial injury with respect to radiographic knee osteoarthritis and patient relevant outcomes.

Methods: Of 219 male soccer players with an ACL injury in 1986, 205 (94\%) were available for follow up after 14 years; $75 \%$ of the cohort (154/205) answered mailed questionnaires (KOOS, SF-36, and Lysholm knee scoring scale) and 122 of these consented to weight bearing radiographs.

Results: Radiographic changes were found in $95(78 \%)$ of the injured knees, while more advanced changes, comparable with Kellgren-Lawrence grade 2 or higher, were seen in 50 (41\%). In the uninjured knees more advanced changes, comparable with Kellgren-Lawrence grade 2 or higher, were seen in five knees (4\%). No differences were seen between surgically and conservatively treated players. The patient relevant outcome was affected and did not differ between subjects with and without radiographic changes. Eighty per cent reported reduced activity level.

Conclusions: A high prevalence of radiographic knee osteoarthritis was seen in male soccer players 14 years after an $\mathrm{ACL}$ disruption. The injury and the osteoarthritis, irrespective of the treatment provided to these patients, often result in knee related symptoms that severely affect the knee related quality of life by middle age.
\end{abstract}

$\Lambda$ ge and female sex are the most prominent risk factors for osteoarthritis over the age of 50 years. ${ }^{12}$ Before 50 , osteoarthritis is more common in men. ${ }^{3}$ Risk factors for osteoarthritis at this young age include major knee injuries and joint loading. ${ }^{4}$ It is estimated that $3.5 \%$ of all people between 35 and 54 years of age have radiological osteoarthritis after knee injuries. ${ }^{6-9}$ Post-traumatic knee osteoarthritis is a good model for studies of the osteoarthritic process: the group is relatively homogeneous in an otherwise heterogeneous osteoarthritis population, the condition is common, and the start of the disease can be identified at the time of the trauma. Disease progression can be followed prospectively.

Anterior cruciate ligament (ACL) tears often influence knee stability. ${ }^{10-13}$ Nearly $40 \%$ of all knee injuries in soccer are ACL injuries ${ }^{14}$ and the affected players are often young. The overall injury rate in soccer has been estimated to be $8-30$ injuries per 1000 game hours and 2-5 injuries per 1000 practice hours. ${ }^{15-17}$

A major knee injury may not only lead to an interrupted soccer career, ${ }^{42}{ }^{18}$ but also to the early development of knee osteoarthritis. Patients with osteoarthritis report handicap in six areas: functional and social activities, relationships, socioeconomic status, emotional wellbeing, and body image. Such patients also report more handicaps in each of the six areas than patients with rheumatoid arthritis. ${ }^{19}$

Our aim in this study was to assess the consequences of an ACL tear 14 years after the initial injury in a cohort of male soccer players with respect to radiographic knee osteoarthritis and patient relevant outcomes, such as activity level, symptoms, function, and quality of life.

\section{METHODS}

\section{Subjects}

The subjects in this nationwide study of ACL injuries were identified in 1989. In Sweden all soccer players participating in league soccer have compulsory insurance through the same company (Folksam). A search was made in the Folksam archives in 1989 for all knee injuries that had occurred in 1986. In all, 937 knee injuries were found. The data from questionnaires and from the hospital records showed a total of 344 ACL injuries, of which 238 were in men and 106 in women. In 2000 the male players were contacted for a 14 year follow up, and 205 were available. The questionnaires were answered by 154, and of those 65 $(42 \%)$ had been treated without surgery, and 89 (58\%) had undergone ACL reconstruction. The most common surgical method was patellar tendon graft. The reasons behind the choice of treatment were not recorded.

In $1989,59(38 \%)$ of the patients were identified as having a meniscus tear combined with their ACL injury. The rupture was medial in 35 cases, lateral in 17 cases, and both in seven cases.

The mean age of the study group at 14 years after the index injury was 38 years (range 30 to 56) (table 1). The subgroup with a combined injury (mean age 38 , range 31 to 54 ) did not differ in age from the study group as a whole $(p=0.4)$, nor did the non-participants differ in age from those participating (mean age 37 years (range 29 to 48 ), $\mathrm{p}=0.7$ ).

\section{Radiographic examination}

Of the 154 subjects, 122 (79\%) consented to have radiographs taken. The main reason for not having radiographs taken was lack of time. Posterior-anterior radiographs with the knees at $15^{\circ}$ of flexion were taken in the weight bearing position, the weight equally distributed on both legs, for examination of

\footnotetext{
Abbreviations: $\mathrm{ACL}$, anterior cruciate ligament; $\mathrm{KOOS}$, knee injury and osteoarthritis outcome score; SF-36, medical outcomes study 36 item short form health survey
} 
Table 1 Characteristics of the study group and the subgroups operated, non-operated, osteoarthritis, and non-osteoarthritis

\begin{tabular}{llllll}
\hline & Study group $(\mathbf{n}=154)$ & Operated $(\mathbf{n}=89)$ & Not operated $(\mathbf{n}=65)$ & OA $(\mathbf{n}=50)$ & Non-OA (n= 104) \\
\hline Age (years) & $38(5.2),(30$ to 56$)$ & $37(4.2),(30$ to 49$)$ & $40(6.2),(30$ to 56$)$ & $39(4.9),(32$ to 53$)$ & $38(5.4),(30$ to 56$)$ \\
Weight $(\mathrm{kg})$ & $83(8.5),(58$ to 110$)$ & $83(8.1),(67$ to 105$)$ & $83(9.0),(71$ to 110$)$ & $85(8.4),(68$ to 108$)$ & $83(8.4),(58$ to 110$)$ \\
Height $(\mathrm{m})$ & $181(6.4),(165$ to 205$)$ & $181(6.8),(165$ to 205$)$ & $181(5.6),(170$ to 193$)$ & $182(6.2),(170$ to 205$)$ & $180(6.3),(165$ to 199$)$ \\
BMl $\left(\mathrm{kg} / \mathrm{m}^{2}\right)$ & $26(2.3),(21$ to 34$)$ & $26(2.3),(21$ to 32) & $26(2.3),(21$ to 34$)$ & $26(2.3),(21$ to 32$)$ & $26(2.3),(21$ to 34$)$ \\
\hline
\end{tabular}

Values are mean (SD), (range).

$\mathrm{BMI}$, body mass index; OA, osteoarthritis.

the tibiofemoral joint. All radiographs were taken with a Siemens basic radiological system (film focus distance $1.4 \mathrm{~m}$; Siemens GmbH, Erlangen, Germany) at $70 \mathrm{kV}$ and $10 \mathrm{~mA}$. All were obtained with the same standardised technique.

The frontal views of the tibiofemoral joint from both knees of the subjects were classified according to the recommendations of the Osteoarthritis Research Society. ${ }^{20}$ A radiographic atlas was used to evaluate the appearance of the joint space and the presence of osteophytes and to grade these features on a scale from 0 to $3 .^{20}$ Radiographic osteoarthritis was defined as joint space narrowing grade 1 combined with osteophytes, or joint space narrowing grade 2 or more. ${ }^{13}$ This definition of osteoarthritis corresponds to Kellgren and Lawrence knee osteoarthritis grade $2 .^{21}$ The same reader (HR) evaluated all the radiographs. The reader was blinded with regard to the injured side in non-operated subjects. In ACL reconstructed subjects the bone tunnels were visible on $x$ ray films. The reader in the present study had been shown in an earlier report to have high agreement with another reader. In the previous study there was agreement for medial joint space narrowing in 119 of 136 knees; for lateral narrowing in 133 of 136 knees; and for osteophytes in 243 of 272 compartments. $^{13}$

\section{Questionnaires}

Three questionnaires were used to evaluate patient relevant outcomes: the disease specific knee injury and osteoarthritis outcome score (KOOS), the generic short form 36 (SF-36), and the Lysholm knee scoring scale. In addition, data including duration of knee problems and current physical activity level at work and recreation were collected. The subjects were also asked to report current activity level (work and recreation) compared with before the knee injury on a five point Likert scale, ranging from much lower to much higher. The players noted the reasons as "knee problem," "other reasons," or "both" if a change in activity level was experienced.

Knee injury and osteoarthritis outcome score (KOOS) The KOOS is a 42 item self administered questionnaire based on the WOMAC osteoarthritis index, ${ }^{22}$ proven valid for subjects with ACL injury and early osteoarthritis. ${ }^{23}{ }^{24}$ The KOOS assesses five separate dimensions: pain, symptoms, activities of daily living, sport and recreation function, and knee related quality of life. A score from 0-100 is calculated for each dimension, with 100 representing best possible score.

\section{SF-36}

The medical outcomes study 36 item short form health survey (SF-36) is a widely used measure of general health which comprises eight subscales: physical functioning, role-physical, bodily pain, general health, vitality, social functioning, role-emotional, and mental health. ${ }^{25}$ The SF-36 has previously been used in studies of subjects with ACL injury. ${ }^{26} \mathrm{~A}$ score from 0 to 100 is calculated for each dimension, 100 representing the best result. The Swedish acute version 1.0 was used..$^{27}$

\section{Lysholm knee scoring scale}

The Lysholm knee scoring scale is an eight item questionnaire developed to assess symptoms and functional disabilities resulting from an ACL injury. ${ }^{28}$ All eight items (pain, instability, locking, stairs, swelling, squat, limp, and support) are aggregated into one score from 0 to 100 , where 100 indicates normal knee function. The Lysholm scale is intended to be observer administered and no patient instructions are provided in the original version. In this study the Lysholm knee scoring scale was patient administered and the subjects were instructed to consider the last week when filling out the questionnaire.

\section{Statistics}

Non-parametric statistics were used. The Kruskal-Wallis test was employed to determine differences for each subscale of the KOOS between groups without or with radiographic osteoarthritis grade 1 to grade 3. The Mann-Whitney U test was used when comparing two groups. A probability (p) value of $\leqslant 0.05$ was regarded as significant.

\section{RESULTS \\ Radiography}

Radiographic changes were found in 95 (78\%) of the injured knees, and of these, radiographic osteoarthritis equivalent to Kellgren and Lawrence grade 2 was seen in $50(41 \%)$. Twenty seven subjects $(22 \%)$ had no radiographic changes at all. No difference in radiographic outcome was determined between those treated with or without surgery.

The subjects who filled out the questionnaires but declined to undergo a radiographic examination did not differ in age, weight, height, or functional status from those who had radiographs taken. Age and BMI did not differ between subjects with different radiographic grading, nor between subjects in the operated or non-operated group (table 1).

Subjects with a meniscus tear had significantly more radiographic changes equivalent to Kellgren and Lawrence grade 2 or worse $(59 \% \vee 31 \%, \mathrm{p}=0.002)$, but the severity of radiographic osteoarthritis between isolated ACL rupture and associated meniscus tear was similar.

\section{Questionnaires}

Only limited problems were noted for the KOOS activity of daily living dimension (table 2). Eighty eight subjects (57\%) had an excellent score for this dimension (defined as 95100 ), while only 28 subjects ( $18 \%$ ) scored excellent in sport/ recreation, and $18(12 \%)$ in knee specific quality of life. The most influenced items in sport/recreation were "What difficulty have you experienced in the last week when turning/twisting on your injured knee?" and "What difficulty have you experienced in the last week when kneeling?" One of four subjects reported severe problems with turning/ twisting at least, and one of three reported severe problems with kneeling at least. Of those reporting problems with kneeling, 59\% were from the operated group and 41\% from the non-operated group. The most affected item in the subscale "knee specific quality of life" was "Have you modified your lifestyle to avoid potentially damaging 
Table 2 Values for the KOOS questionnaire, SF-36, and Lysholm score for the study group, with comparison values for different previously published reference groups

\begin{tabular}{|c|c|c|c|c|c|c|}
\hline & \multicolumn{3}{|l|}{ Study group } & \multicolumn{3}{|c|}{ Reference groups } \\
\hline & Mean (SD) & Range & $95 \% \mathrm{Cl}$ & Mean (SD) & Range & $95 \% \mathrm{Cl}$ \\
\hline $\begin{array}{l}\text { KOOS }(n=154+n=50) \\
\text { Pain* } \\
\text { Symptoms* } \\
\text { ADL }^{*} \\
\text { Sport } / \text { rec }^{*} \\
\text { QOL }\end{array}$ & $\begin{array}{l}84(16.1) \\
76(20.2) \\
90(13.5) \\
63(28.7) \\
60(24.6)\end{array}$ & $\begin{array}{l}(28 \text { to } 100) \\
(14 \text { to } 100) \\
(37 \text { to } 100) \\
(0 \text { to } 100) \\
(6 \text { to } 100)\end{array}$ & $\begin{array}{l}81.9 \text { to } 87.1 \\
72.5 \text { to } 79.0 \\
88.3 \text { to } 92.6 \\
58.9 \text { to } 68.0 \\
56.2 \text { to } 63.9\end{array}$ & $\begin{array}{l}96(9.9) \\
94(9.9) \\
96(10.0) \\
90(17.9) \\
92(13.5)\end{array}$ & $\begin{array}{l}(50 \text { to } 100) \\
(57 \text { to } 100) \\
\text { (47 to } 100) \\
(25 \text { to } 100) \\
(38 \text { to } 100)\end{array}$ & $\begin{array}{l}93.7 \text { to } 99.0 \\
92.3 \text { to } 96.9 \\
93.2 \text { to } 98.5 \\
85.6 \text { to } 95.1 \\
88.6 \text { to } 95.7\end{array}$ \\
\hline $\begin{array}{l}\text { SF-36 ( } n=152+n=948) \\
\text { Physical functioning* } \\
\text { Role-physical* } \\
\text { Bodily pain } \\
\text { General health } \\
\text { Vitality } \\
\text { Social functioning* } \\
\text { Role-emotional } \\
\text { Mental health* }\end{array}$ & $\begin{array}{l}84.5(14.5) \\
81.4(30.9) \\
74.3(22.9) \\
82.1(17.0) \\
70.8(20.8) \\
93.6(13.9) \\
91.0(22.4) \\
86.4(12.9)\end{array}$ & $\begin{array}{l}(35 \text { to } 100) \\
(0 \text { to } 100) \\
(22 \text { to } 100) \\
(15 \text { to } 100) \\
(15 \text { to } 100) \\
(25 \text { to } 100) \\
(0 \text { to } 100) \\
(40 \text { to } 100)\end{array}$ & $\begin{array}{l}82.1 \text { to } 86.8 \\
76.5 \text { to } 86.4 \\
70.6 \text { to } 78.0 \\
79.4 \text { to } 84.8 \\
67.5 \text { to } 74.1 \\
91.3 \text { to } 95.8 \\
87.4 \text { to } 94.6 \\
84.4 \text { to } 88.5\end{array}$ & $\begin{array}{l}93.1(15.4) \\
88.5(26.7) \\
78.2(25.3) \\
78.3(20.2) \\
71.6(21.2) \\
89.5(20.0) \\
89.4(24.3) \\
82.2(18.6)\end{array}$ & $\begin{array}{l}(0 \text { to } 100) \\
(0 \text { to } 100) \\
(0 \text { to } 100) \\
(0 \text { to } 100) \\
(0 \text { to } 100) \\
(0 \text { to } 100) \\
(0 \text { to } 100) \\
(0 \text { to } 100)\end{array}$ & $\begin{array}{l}92.1 \text { to } 94.1 \\
86.7 \text { to } 90.2 \\
76.6 \text { to } 79.8 \\
77.0 \text { to } 79.6 \\
70.2 \text { to } 72.9 \\
88.2 \text { to } 90.8 \\
87.8 \text { to } 91.0 \\
81.0 \text { to } 83.4\end{array}$ \\
\hline Lysholm score $^{*}(n=154+n=131)$ & $77.0(19.1)$ & (9 to 100$)$ & 73.5 to 79.6 & $99(2.7)$ & (77 to 100$)$ & 98.8 to 99.4 \\
\hline
\end{tabular}

For the KOOS questionnaire, reference data are from 59 subjects aged 36 to 79 years obtained in a previous study ${ }^{39}$ For the SF- 36 questionnaire, reference values are for the general Swedish male population aged 35 to 44 years. ${ }^{27}$ For the Lysholm score, reference values are for healthy team athletes aged 13 to 25 years. $^{40}$

${ }^{*}$ Significant difference at $\mathrm{p}<0.05$.

$\mathrm{ADL}$, activities of daily living; Cl, confidence interval; KOOS, knee injury and osteoarthritis outcome score; QOL, knee related quality of life; SF-36, medical outcomes study 36 item short form health survey; Sport/rec, sport and recreation function.

activities to your knee?" Thirty per cent reported severe changes in lifestyle at least because of their knee injury.

The injured players reported significantly worse outcome in the SF-36 subscales "physical functioning" and "rolephysical" compared with Swedish men aged 35 to 44 . However, in the subscales "social functioning" and "mental health," the players scored significantly higher than the reference group ${ }^{27}$ (table 2 ).

A mean score of 77 (range 9 to 100) was obtained in the Lysholm knee scoring scale. Sixty three subjects (41\%) showed excellent or good results (100-84 points). Subjects with radiographic osteoarthritis did not have significantly different scores from subjects without osteoarthritis (table 3).

There was no difference in outcome of the questionnaire between those treated with ACL surgery and those who were not (table 3). A surgically treated meniscus injury in addition to the ACL injury did not influence the outcome as measured by the KOOS, SF-36, or Lysholm questionnaires.

\section{Activity level}

Eighty two subjects (53\%) reported level 2-4, easy to moderate load at work. Eighty four subjects (55\%) reported level 5-6, a high level of recreational activities. One hundred and twenty three subjects $(80 \%)$ reported reduced activity level after the knee injury, and of these the majority (69\%) reported the knee injury as the cause. Subjects with no radiographic changes reported the same workload and recreational activities as subjects with radiographic changes. Twelve $(7.8 \%)$ of the 154 participants were still participating in organised soccer. Of these, nine had been surgically treated and three conservatively treated.

Table 3 Values for the five measured outcomes in the KOOS questionnaire $(n=154)$, the eight measured outcomes in the SF36 questionnaire $(n=152)$, and the outcomes in Lysholm score $(n=154)$ for subjects with and without osteoarthritis and for operated and non-operated subjects

\begin{tabular}{|c|c|c|c|c|c|}
\hline & Study group & $O A(n=50)$ & No OA $(n=72)$ & Operated $(n=89)$ & Non-operated $(n=65)$ \\
\hline \multicolumn{6}{|l|}{$\operatorname{KOOS}(n=154)$} \\
\hline Pain & 84 (81.9 to 87.1$)$ & 85 (80.2 to 89.9$)$ & 84 (81.2 to 87.3$)$ & 86 (82.2 to 89.2 ) & 83 (79.1 to 86.7$)$ \\
\hline Symptoms & 76 (72.5 to 79.0$)$ & 73 (66.9 to 78.7$)$ & 77 (73.3 to 81.1$)$ & 75 (70.4 to 79.6$)$ & 77 (72.3 to 81.2 ) \\
\hline$A^{\prime} L^{\prime}$ & 90 (88.3 to 92.6$)$ & 91 (87.1 to 95.3$)$ & 90 (87.5 to 92.7$)$ & 91 (88.5 to 94.0) & 89 (85.9 to 92.9) \\
\hline Sport/rec & 63 (58.9 to 68.0$)$ & 64 (55.5 to 72.0$)$ & 63 (57.7 to 68.8 ) & $64(57.7$ to 70.1$)$ & 63 (55.9 to 69.6$)$ \\
\hline QOL & 60 (56.2 to 63.9) & 61 (55.1 to 67.2$)$ & $60(54.5$ to 64.6$)$ & 62 (56.6 to 67.1$)$ & $58(51.6$ to 63.6$)$ \\
\hline \multicolumn{6}{|l|}{ SF-36 $(n=152)$} \\
\hline Physical function & 84 (82.1 to 86.8 ) & $84(80.0$ to 88.4$)$ & 85 (81.8 to 87.5$)$ & 84 (80.4 to 86.9 ) & 86 (82.3 to 89.1$)$ \\
\hline Role-physical & 81 (76.5 to 86.4$)$ & 84 (75.1 to 91.4) & 80 (74.2 to 86.6$)$ & 83 (76.4 to 88.9 ) & 80 (71.4 to 87.9 ) \\
\hline Bodily pain & $74(70.6$ to 78.0$)$ & $76(69.0$ to 82.6$)$ & $74(69.1$ to 78.0$)$ & 75 (70.2 to 80.1$)$ & 73 (67.6 to 78.8$)$ \\
\hline General health & 82 (79.4 to 84.8$)$ & 86 (82.2 to 89.8 ) & 80 (76.6 to 83.8$)$ & 82 (78.7 to 85.5$)$ & 82 (77.5 to 86.7$)$ \\
\hline Vitality & $71(67.5$ to 74.1$)$ & 71 (64.8 to 77.2$)$ & 71 (66.7 to 74.7$)$ & $71(67.0$ to 76.1$)$ & 70 (64.8 to 74.8$)$ \\
\hline Social functioning & 94 (91.3 to 95.8$)$ & 96 (92.9 to 99.1$)$ & $92(89.4$ to 95.4$)$ & 93 (90.2 to 96.2$)$ & 94 (90.7 to 97.6$)$ \\
\hline Role-emotional & 91 (87.4 to 94.6 ) & 94 (88.7 to 99.3 ) & 90 (84.4 to 94.2$)$ & 92 (87.8 to 97.1$)$ & 89 (83.3 to 94.8 ) \\
\hline Mental health & 86 (84.4 to 88.5 ) & 88 (84.5 to 91.4) & 86 (83.1 to 88.3$)$ & 87 (84.1 to 89.4$)$ & 86 (82.6 to 89.4$)$ \\
\hline Lysholm scale $(n=154)$ & 77 (73.5 to 79.6$)$ & 76 (71.1 to 81.7 ) & 77 (73.1 to 80.7$)$ & 78 (73.4 to 81.7$)$ & 75 (70.8 to 79.8$)$ \\
\hline
\end{tabular}

Values are mean values (95\% confidence interval).

$\mathrm{ADL}$, activities of daily living; KOOS, knee injury and osteoarthritis outcome score; QOL, knee related quality of life; SF-36, medical outcomes study 36 item short form health survey; Sport/rec, sport and recreation function. 


\section{DISCUSSION}

The purpose of this report was to identify the consequences of an ACL tear in a cohort of male soccer players 14 years after the initial injury with respect to radiographic knee osteoarthritis, activity level, and patient related symptoms. The cohort was from the Swedish population of soccer players. They have all been followed for 14 years after the initial injury, with specific follow ups after three and seven years. The results reflect the severe consequences of an ACL injury in middle aged male former soccer players. Nearly $80 \%$ of the cohort had significant radiographic changes in the knee, and more than $40 \%$ fulfilled the criteria for definite radiographic osteoarthritis. The majority suffered from knee symptoms affecting their knee related quality of life.

Most studies describe only radiographic knee osteoarthritis, but in the present study the patient relevant outcome was taken into consideration. We also analysed the patient relevant outcome and activity level in relation to the radiographic knee osteoarthritis.

This is a nationwide study of ACL injuries in Swedish male soccer players. All players were injured in 1986, and the cohort was identified in 1989. They were previously followed up in $1993 .{ }^{12}$

A limitation of the study was the response rate. Of 205 male soccer players located, $75 \%$ responded to the questionnaires, but of these, 36 did not accept the invitation to radiographic examination. Of all 238 male soccer players with an ACL injury in 1986, $122(51 \%)$ consented to have a radiograph taken in 2000 . This may constitute a selection bias, with an increased interest in participating in the study if symptoms from the knee joint were present. However, the information from the questionnaires did not support the theory that the group who did not have radiographs taken had less or more knee symptoms than the group who had radiographs taken.

The treatment of the subjects with or without surgery was not randomised, limiting the interpretation of differences, or lack of differences, between these groups.

There are difficulties in comparing studies with regard to osteoarthritis prevalence, mainly because of factors such as different radiographic techniques and classifications. There can also be differences in patient material and in the time of follow up. This study is unique, as all subjects have been followed during the same span of time. The results are in agreement with other studies on osteoarthritis after an ACL injury. ${ }^{14} 2930$

Male soccer players have an increased risk of knee osteoarthritis. ${ }^{29}{ }^{31-33}$ Injuries to the menisci and cruciate ligaments are believed to be the main reason for this, but also when injuries are excluded, a relation between elite soccer and osteoarthritis persists. ${ }^{32}$ This means that a player who returns to soccer after an ACL injury has an even higher risk of osteoarthritis, both because of the soccer itself and because of the injury. Kohatsu and Schurman reported in a case-control study that osteoarthritis cases were almost five times more likely to have had a significant knee injury than the controls. ${ }^{1}$ The natural course of an ACL injury in relation to the risk of developing osteoarthritis is not known. Further research is required to understand the different mechanisms whereby some individuals develop osteoarthritis and others do not. Sensitive instruments are needed to monitor the process, such as magnetic resonance imaging with specific sequences or biomarkers. Our study has not covered these issues.

Our study population reported similar symptoms to patients on the waiting list for ACL reconstruction-for example, pain and functional limitations. ${ }^{24}$ However, our population with chronic ACL injury reported a better knee related quality of life than the group with an acute tear, possibly because of reduced activity level and an acceptance of their reduced knee function. ${ }^{23} 24$

This study cohort was followed up in 1993, seven years after their index injury. ${ }^{12}$ At this time, 49 subjects (32\%) were still participating in organised soccer, compared with 12 $(7.8 \%)$ in the present 14 year follow up. One reason for this is that as the subjects get older they have families and have less time for soccer.

At the 14 year follow up the subjects reported better knee function than they did at the seven year follow up: a mean score of 77 (range 9 to 100) was obtained in the Lysholm knee scoring scale in the present follow up, compared with 66 (4 to 100) in the seven year follow up. Sixty three subjects in the present study $(41 \%)$ reported excellent or good results ( 100 to 84 points) compared with 49 (32\%) at the seven year follow up. Perhaps the reason for this is that most subjects had stopped playing soccer and that they had learned to live with their knee problems.

There was no detectable difference in the prevalence of osteoarthritis or symptoms between subjects who had undergone knee surgery and those who had not. This finding was expected as there are no published data supporting a preventive effect of reconstructive ACL surgery against osteoarthritis. On the contrary, a study by Daniel et al in 1994 showed a trend towards a greater prevalence of osteoarthritis in surgically treated than in non-surgically treated patients. ${ }^{34}$ An increased ability to return to soccer following surgical reconstruction may be disadvantageous with regard to the risk for developing knee osteoarthritis. ${ }^{32}$ Subjects with an ACL rupture and a meniscus tear had a higher prevalence of radiographic osteoarthritis than those with an isolated ACL rupture. This was as expected and in accordance with other studies. ${ }^{35} 36$

The need for osteotomy and knee arthroplasty will arise well before the age of 50 in many of the subjects in this cohort. Considering that soccer is the most commonly played athletic game in the world, the risk of a latent and growing group of osteoarthritis patients is high. For this group of young people of working age, the indirect costs at an individual level, and also for society, will be considerable. Thus the prevention of knee injuries appears to be very important to prevent soccer players from getting early osteoarthritis and knee related symptoms. The results of the present study, and of others ${ }^{14} 303237$ that have shown significant radiographic osteoarthritis in young former soccer players, must be considered alarming.

\section{ACKNOWLEDGEMENTS}

This study was supported by the Zoega Foundation, Swedish National Centre for Research in Sport, the Gorton Foundation, and the Medical Faculty of the University of Lund.

\section{Authors' affiliations}

A von Porat, Department of Physical Therapy, Lund University Hospital, Lund, Sweden

E M Roos, Department of Orthopaedics, Lund University Hospital

H Roos, Hospital of Helsingborg, Helsingborg, Sweden

\section{REFERENCES}

1 Kohatsu ND, Schurman DJ. Risk factors for the development of osteoarthritis of the knee. Clin Orthop Rel Res 1990;261:242-6.

2 Felson DT. The course of osteoarthritis and factors that affect it. Osteoarthritis Cartilage 1993;19:607-15.

3 Felson DT, Lawrence RC, Dieppe PA, Hirsch R, Helmick CG. Osteoarthritis: the disease and its prevalence and impact. Ann Intern Med 2000;133:635-46.

4 Sandmark $H$, Vingård E. Sports and risk for severe osteoarthritis of the knee. Scand J Med Sci Sports 1999;9:279-84.

5 Cooper C, Snow S, McAlindon TE, Kellingrey S, Stuart B, Coggon D, et al. Risk factors for the incidence and progression of radiographic knee osteoarthritis. Arthritis Rheum 2000;43:995-1000. 
6 Williams M, Frankel S, Nanchahal K, Coast J, Donovan J. Total knee replacement. In: Stevens A, Raferty J, eds. Health needs assessment, vol 1. Oxford: Radcliffe, 1994:448-523.

7 Tzonchev VT, Pilossoff T, Kanev. Prevalence of osteoarthritis in Bulgaria in population studies of the rheumatic diseases. Amsterdam: Excerpta Medica Foundation, 1968

8 Hernborg JS, Nilsson BE. Age and sex incidence of osteophytes in the knee joint. Acta Orthop Belg 1973;44:66-8.

9 HANES. Basic data on osteoarthritis of the knee, hip and sacroiliac joints in adults aged 25-74 years. USA 1971-75. Nat Center Health Stat 1979:series $11(213)$.

10 Graham GP, Fairclough JA. Early osteoarthritis in young sportsmen with severe anterolateral instability of the knee. Injury 1988; 19:247-8.

11 Kannus $\mathbf{P}$, Järvinen $M$. Age, overweight, sex and knee instability: their relationship to the post-traumatic osteoarthritis of the knee joint. Injury 1988; 19:105-8.

12 Roos H, Ornell M, Gärdsell P, Lohmander S, Lindstrand A. Soccer after anterior cruciate ligament - an incompatible combination. Acta Orthop Scand 1995:66:107-12

13 Roos H, Laurén M, Adalberth T, Roos EM, Jonsson K, Lohmander SL. Knee osteoarthritis after meniscectomy. Prevalence of radiographic changes after twenty-one years, compared with matched controls. Arthritis Rheumatism 1998:41:687-93.

14 Roos H, Adalberth T, Dahlberg L, Lohmander SL. Osteoarthritis of the knee after injury to the anterior cruciate ligament or meniscus: the influence of time and age. Osteoarthritis Cartilage 1995;3:261-7.

15 Ekstrand J, Gillquist J, Möller M, Öberg B, Liljedahl S-O. Incidence of soccer injuries and their relation to training and team success. Am J Sports Med 1983;11:63-7.

16 Arendt E, Randall D. Knee injury patterns among men and women in collegiate basket and soccer: NCAA data and review of literature. Am J Sports Med 1995; 23:694-701.

17 Árnason Á, Gudmundsson Á, Dahl HA, Jóhannsson E. Soccer injuries in Iceland. Scand J Med Sci Sports 1996;6:40-5.

18 Engström B, Johansson C, Törnkvist $H$. Soccer injuries among elite female players. Am J Sports Med 1991;19:372-5.

19 Carr AJ. Beyond disability: measuring the social and personal consequences of osteoarthritis. Osteoarthritis Cartilage 1999;7:230-8.

20 Altman RD, Hochberg M, Murphy WA, Wolfe F, Lequesne M. Atlas of individual radiographic features in osteoarthritis. Osteoarthritis Cartilage 1995;3(suppl A):3-70

21 Kellgren J, Lawrence J. Radiological assessment of osteoarthrosis. Ann Rheum Dis 1957; 16:494-502.

22 Bellamy N, Watson Buchanan W, Goldsmith C, Campbell J, Stitt L. Validation study of WOMAC: a health status instrument for measuring clinically important patient relevant outcomes to antirheumatic drug therapy in patient with osteoarthritis of the hip or the knee. J Rheumatol 1988;15:1833-40.

23 Roos EM, Roos H, Ekdahl C, Lohmander SL. Knee injury and osteoarthritis outcome score (KOOS) - validation of a Swedish version. Scand J Med Sci Sports 1998;8:439-48.
24 Roos EM, Roos H, Lohmander SL, Ekdahl C, Beynnon BD. Knee injury and osteoarthritis outcome score (KOOS) - development of a self-administered outcome measure. J Orthop Sports Phys Ther 1998;78:88-96.

25 Ware JE, Sherbourne CD. The MOS 36-item short form health survey (SF-36) I. Conceptual framework and item selection. Med Care 1992;30:472-83.

26 Shapiro ET, Richmond JC, Rockett SE, McGrath MM, Donaldson WR. The use of a generic patient-based health assessment (SF-36) for evaluation of patients with anterior cruciate ligament injuries. Am J Sports Med 1996;24:No 2, 196-200.

27 Sullivan M, Karlsson J, Ware JE. The Swedish SF-36 health survey-I. evaluation of data quality, scaling assumptions, reliability and construct validity across general populations in Sweden. Soc Sci Med 1995:41:1349-58

28 Tegner $Y$, Lysholm J. Rating systems in the evaluation of knee ligament injuries. Clin Orthop Rel Res 1985;198:43-9.

29 Neyret P, Donell ST, DeJour D, DeJour H. Partial meniscectomy and anterior cruciate ligament rupture in soccer players. A study with a minimum 20-year followup. Am J Sports Med 1993;21:455-60.

30 Segawa H, Omori G, Koga Y. Long-term results of non-operative treatment of anterior cruciate ligament injury. Knee 2000;8:5-11

31 Ferretti A, Conteduca F, De Carli A, Fontana M, Mariani PP. Osteoarthritis of the knee after ACL reconstruction. Int Orthop 1991;15:367-71.

32 Roos H, Lindberg H, Gärdsell P, Lohmander SL, Wingstrand H. The prevalence of gonarthrosis and its relation to meniscectomy in former soccer players. Am J Sports Med 1994;22:219-22.

33 Kujala UM, Kaprio J, Sarna S. Osteoarthritis of weight bearing joints of lower limbs in former elite male athletes. BMJ 1994;308:231-4.

34 Daniel DM, Stone ML, Dobson BE, Fithian DC, Rossman DJ, Kaufman KR. Fate of the $\mathrm{ACL}$ injured patient: a prospective outcome study. Am J Sports Med 1994;22:632-44.

35 Shelbourne KD, Gray T. Results of anterior cruciate ligament reconstruction based on meniscus and articular cartilage status at the time of surgery. Five- to fifteen-year evaluations. Am J Sports Med 2000;28:446-52.

36 Wu WH, Hackett T, Richmond JC. Effects of meniscal and articular surface status on knee stability, function, and symptoms after anterior cruciate ligament reconstruction: a long-term prospective study. Am J Sports Med 2002:30:845-50.

37 Sherman MF, Warren RF, Marshall JL, Savatsky GJ. A clinical and radiographical analysis of 127 anterior cruciate insufficient knees. Clin Orthop Rel Res 1988;227:229-37.

38 Gelber AC, Hochberg MC, Mead LA, Wang N-Y, Wigley FM, Klag MJ. Joint injury in young adults and risk for subsequent knee and hip osteoarthritis. Ann Intern Med 2000;133:321-8.

39 Englund M, Roos EM, Lohmander LS. Impact of type of meniscal tear on radiographic and symptomatic knee osteoarthritis: a sixteen-year followup of meniscectomy with matched controls. Arthritis Rheum 2003;48:2178-87.

40 Demirdjian AM, Petrie SG, Guanche CA, Thomas KA. The outcomes of two knee scoring questionnaires in a normal population. Am J Sports Med $1998 ; 26: 46-51$ 